\title{
A Case of Restless Legs Syndrome in the Setting of Long-Term Care and Dementia
}

\author{
Joshua Fauchera, Paul Y. Takahashi ${ }^{\text {b, c }}$
}

\begin{abstract}
Restless Legs Syndrome (RLS) is a common disorder that physicians frequently encounter in an outpatient clinic. Within long-term care, there are unique challenges to caring for residents with RLS. An 87-year-old woman with dementia and a history of RLS and nocturnal agitation, resided in a long-term care setting and experienced nighttime agitation and aggression towards staff, coupled with cognitive decline. Her agitation was possibly a result of inadequate treatment of longstanding RLS or worsening of her dementia. On account of her dementia, she was unable to communicate her symptoms. Current diagnostic criteria for RLS require patient reports of subjective symptoms. Patients must describe their feelings within the legs, which helps to clarify the diagnosis. Our case illustrates the difficulty of diagnosing restless legs in patients with dementia and communication difficulties, and the need for empiric treatment.
\end{abstract}

Keywords: Elderly; Restless leg syndrome; Dementia; Long term care

\section{Introduction}

Restless Legs Syndrome (RLS) is an idiopathic neurologic disorder. Its prevalence increases with age to affect over $19 \%$ of people older than 80 years [1]. As an age-related disorder, RLS is often seen in long-term care patients. RLS has hallmark features of discomfort or paresthesias in the lower legs that are relieved by movement. RLS is also commonly associated with observable periodic limb movements of sleep,

\footnotetext{
Manuscript accepted for publication September 24, 2012

${ }^{a}$ Mayo Medical School, Mayo Clinic, Rochester, MN, USA

${ }^{\mathrm{b}}$ Division of Primary Care Internal Medicine, Mayo Clinic, Rochester, MN, USA

${ }^{\mathrm{c}}$ Corresponding author: Paul Y. Takahashi, Division of Primary Care Internal Medicine, Mayo Clinic, 200 First Street SW, Rochester, MN 55905, USA. Email: takahashi.paul@mayo.edu
}

doi: http://dx.doi.org/10.4021/jmc901w which are involuntary stereotyped jerking movements of the limbs.

Dementia is also extremely common in long-term care settings, with prevalence in residents 65 years and older recently measured at $45 \%$ for men, and $52 \%$ for women [2]. In patients with dementia, having RLS as a comorbidity has been associated with nocturnal agitation behavior [3]. These disruptions can create problems for nursing home residents including sleep deprivation and a decreased quality of life. Our case demonstrates this type of situation, along with the diagnostic difficulties surrounding RLS in patients with dementia.

\section{Case Report}

Our patient is an 87-year-old woman with a history of dementia and challenging behavior who lives in a skilled nursing facility. Her past history included difficulties with sleep disruptions. In 2000, she stated that she had experienced symptoms of RLS since her teenage years. She was living independently in her home and took gabapentin and carbidopa/levodopa to treat her RLS symptoms. Later in 2001, her gabapentin was tapered off and her carbidopa/levodopa dosage was increased to counter worsening RLS symptoms. In 2003, pramipexole was added to her treatment, and in 2006, carbidopa/levodopa was discontinued while continuing pramipexole. In September 2008, she was admitted to the hospital for atrial fibrillation, and the hospital team noted problems in her memory and executive function, which her family confirmed had developed over a period of years. After dismissal from the hospital, she returned home but refused home health care. In November 2008, she experienced a fall and was eventually discharged to a long-term care (LTC) facility in light of further decline in memory.

Her RLS symptoms started to worsen while she was in LTC. In 2010, the medical team started treatment with gabapentin. She experienced agitation, which disrupted her sleep and provoked aggression towards staff. She was prescribed quetiapine for the agitation, presumed secondary to her dementia, but these symptoms persisted. The patient was unable to communicate any subjective experience of 
RLS symptoms, due to her cognitive decline. The primary concerns from the medical and nursing teams involved the potential challenges of RLS, as well as her dementia. The team increased the pramipexole, which helped improve her symptoms of agitation.

\section{Discussion}

Current diagnostic criteria for RLS, published by the National Institute of Health and the International Restless Legs Syndrome Study Group (IRLSSG), are based entirely on the subjective accounts of symptoms by patients [4]. These diagnostic criteria are not applicable to patients with difficulties in memory, cognition, or communication. Patients with dementia and concurrent RLS have been previously shown to be incapable of reliably answering questions during an RLS diagnostic interview [5]. The IRLSSG also offered diagnostic criteria for patients with cognitive impairment, essentially consisting of observed patterns of behavior suggesting the subjective experience of RLS detailed in the diagnostic criteria for typical patients. Unfortunately, these criteria have not been formally studied or validated, like those applying to the general population [4].

These circumstances suggest that numerous patients with dementia and RLS are at-risk of delayed diagnosis and treatment, exacerbating their sleep disruption and cognitive difficulties, and leading to a decreased quality of life. Positive results from more objective diagnostic modalities, involving immobilization combined with electromyography, have been shown to be correlated with RLS in the past [6], but a large scale assessment showing the value of these tests has not yet been completed. Empiric treatment may be necessary for patients with cognitive impairment who are also thought to suffer from RLS, particularly in LTC settings. Nursing home providers should attempt treatment or modifications of treatment for RLS in appropriate residents. Observation by family and nursing staff is essential to evaluate improvement in the resident's quality of life.

RLS has notably been found to be correlated with iron deficiency [7]. Providers should screen for iron deficiency in all patients with suspected RLS, and residents should receive iron supplementation when their serum ferritin is below $50 \mu \mathrm{g} / \mathrm{L}$ [8]. Our patient experienced RLS continuously throughout her life, including when her serum ferritin was measured at $136 \mu \mathrm{g} / \mathrm{L}$ in 2004, suggesting her symptoms had a different etiology.

First-line pharmacologic therapy for RLS includes dopamine agonists, such as pramipexole [9] and ropinirole [10], titrated upwards to a suitable dose. These agents commonly result in an augmentation effect, with symptoms appearing earlier in the day and medication effectiveness decreasing over time $[11,12]$. This effect creates the challenging need to modify medications in residents who cannot communicate symptoms. The treatment regimen for our patient's RLS included pramipexole for several years, and as her symptoms have worsened, an appropriate adjunct, gabapentin, was added.

Levodopa/carbidopa can also be used as a baseline treatment for intermittent RLS [8, 13]. Unfortunately, augmentation and rebound symptoms in the morning commonly develop with this treatment [13]. Clonazepam can be a useful adjunct therapy in patients with additional causes of poor sleep, with temazepam being recommended for patients with late-night awakenings [8]. These long-acting benzodiazepines may not be ideal in residents with dementia, due to their adverse effects on cognition and risk of falls. Opioids should be reserved for treatment in refractory cases of RLS, with codeine or tramadol to start, and higher-strength opioids used only in the most refractory cases [8]. Again, the risk of falls and sedation should be considered with opioids. Some medications commonly used in LTC may worsen RLS, including antidepressants, neuroleptics, dopamine agonists, and sedating antihistamines [8]. These should be discontinued if possible.

\section{Conclusion}

With the subjective nature of accepted diagnostic criteria, there is a high-risk of RLS going unnoticed or untreated in LTC patients with dementia. RLS can be a significant contributor to sleep disturbance, agitation, and decreased quality of life in these patients. There is a need for further research to validate objective criteria for RLS diagnosis in patients such as ours, who experience cognitive and communication difficulties due to their dementia. Nevertheless, many treatment options exist for RLS, and they may be pursued empirically in patients with dementia and possible RLS, even in the face of inapplicable diagnostic criteria.

\section{Conflict of Interest}

The authors have none to report.

\section{References}

1. Phillips B, Young T, Finn L, Asher K, Hening WA, Purvis $C$. Epidemiology of restless legs symptoms in adults. Arch Intern Med. 2000;160(14):2137-2141.

2. Moore KL, Boscardin WJ, Steinman MA, Schwartz JB. Age and sex variation in prevalence of chronic medical conditions in older residents of U.S. nursing homes. J Am Geriatr Soc. 2012;60(4):756-764.

3. Rose KM, Beck C, Tsai PF, Liem PH, Davila DG, Kleban M, Gooneratne NS, et al. Sleep disturbances and nocturnal agitation behaviors in older adults with de- 
mentia. Sleep. 2011;34(6):779-786.

4. Allen RP, Picchietti D, Hening WA, Trenkwalder C, Walters AS, Montplaisi J. Restless legs syndrome: diagnostic criteria, special considerations, and epidemiology. A report from the restless legs syndrome diagnosis and epidemiology workshop at the National Institutes of Health. Sleep Med. 2003;4(2):101-119.

5. Richards K, Shue VM, Beck CK, Lambert CW, Bliwise DL. Restless legs syndrome risk factors, behaviors, and diagnoses in persons with early to moderate dementia and sleep disturbance. Behav Sleep Med. 2010;8(1):4861.

6. Montplaisir J, Boucher S, Nicolas A, Lesperance P, Gosselin A, Rompre P, Lavigne G. Immobilization tests and periodic leg movements in sleep for the diagnosis of restless leg syndrome. Mov Disord. 1998;13(2):324329.

7. Sun ER, Chen CA, Ho G, Earley CJ, Allen RP. Iron and the restless legs syndrome. Sleep. 1998;21(4):371-377.

8. Silber MH, Ehrenberg BL, Allen RP, Buchfuhrer MJ, Earley CJ, Hening WA, Rye DB. An algorithm for the management of restless legs syndrome. Mayo Clin Proc. 2004;79(7):916-922.

9. Winkelman JW, Sethi KD, Kushida CA, Becker PM, Koester J, Cappola JJ, Reess J. Efficacy and safety of pramipexole in restless legs syndrome. Neurology. 2006;67(6):1034-1039.

10. Trenkwalder C, Garcia-Borreguero D, Montagna P, Lainey E, de Weerd AW, Tidswell P, Saletu-Zyhlarz G, et al. Ropinirole in the treatment of restless legs syndrome: results from the TREAT RLS 1 study, a 12 week, randomised, placebo controlled study in 10 European countries. J Neurol Neurosurg Psychiatry. 2004;75(1):92-97.

11. Ondo W, Romanyshyn J, Vuong KD, Lai D. Long-term treatment of restless legs syndrome with dopamine agonists. Arch Neurol. 2004;61(9):1393-1397.

12. Winkelman JW, Johnston L. Augmentation and tolerance with long-term pramipexole treatment of restless legs syndrome (RLS). Sleep Med. 2004;5(1):9-14.

13. Guilleminault C, Cetel M, Philip P. Dopaminergic treatment of restless legs and rebound phenomenon. Neurology. 1993;43(2):445. 